\title{
Contribuições da concepção dos fenômenos complexos para o ensino dos esportes coletivos
}

\author{
Rafael Pombo Menezes ${ }^{1,2}$ \\ ${ }^{1}$ Grupo de Estudos e Pesquisas de Handebol (GEHAND), Faculdade de Educação \\ Física da UNICAMP, Campinas, SP, Brasil \\ ${ }^{2}$ Grupo de Estudos e Pesquisas de Esportes Coletivos (GEPEC), Curso de Educação \\ Física, Faculdade de Educação do Centro Universitário Nossa Senhora do Patrocínio, \\ Itu, SP, Brasil
}

\begin{abstract}
Resumo: Há tempos os Jogos Coletivos Esportivizados (JCE's) são considerados ou analisados em função das partes que os compõem. Esse pensamento reducionista, caracterizado pelo comportamento linear entre o estímulo e sua resposta, vem passando por significativa mudança de paradigma, principalmente quando estão os JCE's no cerne da análise. O objetivo desta pesquisa é apresentar as relações e as contribuições existentes entre a mudança de paradigma, que passa a considerar a complexidade dos sistemas, e os métodos de ensino dos JCE's, considerando a aleatoriedade, a não-linearidade e a imprevisibilidade inerentes a esses.
\end{abstract}

Palavras-chave: Educação Física. Jogos Coletivos Esportivizados. Pedagogia do Esporte. Sistemas Dinâmicos. Complexidade.

\section{Contributions of the complex phenomena conception to the teaching of team sports}

\begin{abstract}
For long years the Collective Sports (CS) are considered and analyzed according to the parties that compose them. This reductionist thinking, characterized by the linear relationship between the stimulus and its response, has been undergoing a significant paradigm shift, especially when they are the CS at the center of the analysis. The objective of this research is to present the relations and contributions between the paradigm shift, which is now considered the complexity of the systems and methodologies for the CS teaching, considering some properties of these, like the randomness, the non-linearity and unpredictability.

Key words: Physical Education. Collective Sports. Sports Pedagogy. Dynamics Systems. Complexity.
\end{abstract}

\section{Introdução}

Os Jogos Coletivos Esportivizados (JCE's, termo que se refere aos "jogos que foram esportivizados", segundo REIS, 1994, p.3), classe na qual estão inseridas modalidades como o handebol, o futebol, o futsal, o basquetebol entre outras, estão a cada dia mais em evidência devido a fatores como a sua espetacularização e a veiculação em programas específicos em diferentes meios de comunicação, apresentando tanto o conteúdo voltado ao alto rendimento como o conteúdo de relevância social. Essa atenção dada aos JCE's também aumenta o interesse de pesquisadores de diferentes áreas, principalmente a partir do início da década de 80 , a buscar respostas para as ações e combinações técnico-táticas dos jogadores e das equipes, como é o caso do desenvolvimento dos modelos de análise de jogo.

A análise de jogo é uma grande área de pesquisa nos esportes que objetiva 0 desenvolvimento de ferramentas e metodologias que possibilitem a aquisição de parâmetros (como os referentes à preparação física, técnica e/ou tática) relevantes às diferentes modalidades, sejam esses parâmetros de ordem individual (como a análise da técnica do lançamento de martelo reportadas por Gutiérrez-Dávila et al., 2003; e Mercadante et al., 2007) ou coletiva (como a quantificação de distâncias percorridas e velocidades de jogadores de handebol apresentadas nos trabalhos de PERS et al., 2002; e de MENEZES, 2007).

Esses modelos de análise de jogo buscam ao máximo o mapeamento de variáveis que determinem a excelência esportiva e são aplicados pelos membros de uma comissão técnica, como os treinadores e os preparadores físicos na tentativa de compreender, em situações competitivas, o comportamento de algumas variáveis de interesse sem critérios bem definidos para sua identificação.

Hughes e Franks (1997) pesquisaram o recordatório da performance de jogadores por 
técnicos experientes e inexperientes, e concluíram que os técnicos experientes obtiveram maior índice de falsas respostas em relação aos inexperientes, atestando para a fragilidade e a limitação da memória humana. Dessa forma, os autores afirmam que historicamente as intervenções feitas pelos técnicos em suas modalidades são baseadas em observações subjetivas, muitas vezes sem a sistematização de critérios. Para Menezes e Reis (2010, p.458) as "avaliações subjetivas estão predispostas a erros por parte dos treinadores", principalmente por considerar a ocorrência das ações ou dos fatores de forma isolada (ou de forma reducionista, como aponta SANTANA, 2005), ou alienados do cenário técnico-tático em que são expressos durante o jogo.

Esses mesmos JCE's apresentam como uma de suas características mais instigantes a predominância de comportamentos aleatórios dos jogadores, como as movimentações desses e o desenvolvimento de suas ações em decorrência de uma dada situação-problema. Outra característica fundamental na sua problematização está relacionada com as descontínuas tomadas de decisão dos jogadores, mas que estão contextualizadas com a resolução de cada situação-problema no cenário técnicotático do jogo, o que sugere um alto grau de complexidade para a compreensão da dinâmica desses JCE's. Garganta (1998) afirma que essa descontinuidade está relacionada com os acontecimentos anteriores e com as probabilidades dos acontecimentos posteriores, ou seja, as tomadas de decisão dos jogadores são desencadeadas pelas situações instantâneas e pelas ações anteriores e que, assim, influenciarão os demais jogadores em optar pela mudança ou pela continuidade do panorama da situação-problema inerente ao cenário apresentado.

Garganta (1995, p.15), ao citar Teodorescu (1984), afirma que a equipe deve "ser entendida como um microsistema social complexo e dinâmico", no qual o somatório dos valores individuais não representa as relações de um grupo. Sendo assim, considerar as ações isoladas dos jogadores pode não representar suas interrelações com as estruturas do jogo e, da mesma forma, ao somarmos as qualidades técnicas de cada um desses não necessariamente serão obtidos resultados satisfatórios em nível tático. Entende-se, então, que se há um caráter dinâmico no jogo e que o mesmo é dotado de relações complexas, seu reducionismo a uma ou outra variável no que se refere à análise (como sendo essa apenas técnica) ou ao método de ensino, tornaria a caracterização do jogo completamente descontextualizada dos objetivos e das problematizações técnico-táticas de seu cenário.

O caráter dinâmico do jogo é influenciado diretamente pelas tomadas de decisão dos jogadores e, conseqüentemente, pelas respostas técnico-táticas dadas pelos adversários em detrimento das situações-problemas com as quais se deparam. A tomada de decisão no esporte, segundo Araújo (2009, p.538), "emerge num processo contínuo e cíclico de procura de informação para agir, e agir para detectar a melhor informação", o que em termos práticos pode ser relacionada, por exemplo, com a atitude de um atacante que apenas se movimenta em uma determinada direção e que o defensor responsável pela sua marcação pode ou não deslocar-se na mesma direção. O deslocamento ou não do defensor para aquela referida direção sugere outras possibilidades de intervenção não apenas para 0 atacante referido, mas também pode influenciar todo o contexto técnico-tático do jogo, uma vez que há a relação com os demais companheiros de equipe e com os adversários.

É necessário, então, modificar a visão restrita do jogo apenas referenciada no movimento, no gesto técnico, ou na apresentação da habilidade motora, mas buscar a análise dos seus significados em uma relação dinâmica (GONCCALVES et al., 1995) e interconectada com outras ações na busca da resolução de uma situação-problema. Essa visão restrita da explicação de um evento tende a apontar única solução, restrição ou argumento, muitas vezes não evidenciando outros eventos que, ao serem considerados conjuntamente, podem fornecer parâmetros igualmente importantes.

O objetivo desta pesquisa é apontar as relações entre os métodos de ensino dos JCE's e a complexidade envolvida nos fenômenos aleatórios e simultâneos do jogo, considerando a não-linearidade de ocorrência dos eventos em detrimento das tomadas de decisão dos jogadores.

\section{Os sistemas dinâmicos}

Tôrres (2005, p.1) cita que hoje vivemos uma crise de percepção, pois nós e nossos líderes 
conduzimos nossas ações e interações "orientados pelos conceitos de uma visão de mundo obsoleta [...] para lidarmos com nosso mundo, que é cada vez mais complexo". Essa afirmação também pode ser aplicada ao âmbito esportivo, principalmente ao verificarmos as contraposições históricas referentes às métodos de ensino dos JCE's, posteriormente abordadas.

De acordo com Munné (1994) o que é considerado novo, pelo menos em alguns campos da ciência, é o fato de considerar os fatores complexos, principalmente pela complexidade surgir "como dificuldade, como incerteza e não como uma clareza e como resposta" (MORIN, 2003, p.177). Essa mudança de paradigma que está sendo apresentada na ciência, de considerações simples (ou paradigma tradicional) para a compreensão da complexidade dos fenômenos, é "o reconhecimento de que a simplificação obscurece as inter-relações de fato existentes entre todos os fenômenos do universo e de que é imprescindível ver e lidar com a complexidade do mundo em todos os seus níveis" (VASCONCELLOS, 2002, p. 101). Sobre os estudos dos mais diversificados problemas da atual época, Capra (1996, p. 23) afirma que quanto mais os estudamos, "mais somos levados a perceber que eles não podem ser entendidos isoladamente", o que aponta para fatores como a interdependência e a ligação entre esses.

Pesquisadores na área da Física interessaram-se por estudar a dinâmica não-linear de alguns fenômenos, o que, segundo Gleria et al. (2004, p.99), provocou o surgimento de "novos ramos da física, como a teoria do caos e a física dos sistemas complexos". Desde então, outras diversas áreas apropriaram-se dessas discussões na tentativa de compreender melhor os respectivos fenômenos.

Gonçalves et al. (1995), apoiaram-se na teoria dos sistemas dinâmicos para afirmar, a partir de uma revisão de literatura da área de desenvolvimento motor, que o processo de desenvolvimento deve ser visto como nãoestacionário e sendo influenciado por outros sistemas que compõem o organismo e pelo meio onde está inserido. Os mesmos afirmam que a dificuldade para aceitar explicações lineares e pré-determinadas para o desenvolvimento motor é, portanto, cada vez mais plausível, assim como ao analisarmos os JCE's.
Mais recentemente Pakenas et al. (2007) investigaram a aplicação dos conceitos dos sistemas não-lineares relacionados com o exercício físico. Especialmente ao se referirem à homeostase ou ao controle da freqüência cardíaca os autores afirmam que, em condições normais, os mecanismos que regulam essas funções comportam-se em desequilíbrio, que é uma característica dos sistemas não-lineares. Os autores ressaltam, ainda, duas propriedades dos sistemas lineares: a proporcionalidade ("a resposta e o estímulo possuem, num par ordenado, comportamento linear", PAKENAS et al., 2007, p.332) e a superposição (que é a compreensão de sistemas compostos por diversos fatores a partir do estudo de suas partes isoladamente).

Godoy et al. (2005) apoiaram-se na teoria dos sistemas dinâmicos na análise da freqüência cardíaca por métodos baseados na teoria do caos como forma de prognóstico de casos de morbidade em pacientes após cirurgia miocárdica, baseando-se em observações que sugerem que a regulação cardiovascular seja dependente de vários fatores, que interagem entre si de forma não-linear. Os autores afirmam que, apesar de ser um modelo que necessita de investigações por prazos de tempo maiores e com um número maior de sujeitos, esse pode ser transformado em uma poderosa ferramenta de avaliação.

Algumas soluções podem ser encontradas quando da fragmentação do estudo de um sistema dinâmico ao qual é inerente o fator da complexidade. Pakenas et al. (2007, p.333) apontam que essa prática pode trazer problemas, pois "quando os componentes sistêmicos são individualizados, é destruída a principal característica dos sistemas complexos: a cooperação entre as partes". A partir dessa afirmação dos autores que se referem aos estudos dos sistemas corporais entende-se, para o contexto desta pesquisa, que o conceito de "cooperação entre as partes" seja um dos pontos de ligação entre os sistemas dinâmicos e os JCE's.

\section{As relações entre os sistemas dinâmicos e os JCE's}

Um JCE, independente de sua conotação (de lazer, de iniciação esportiva, de reabilitação, ou ainda quando assumem a característica de esporte de rendimento, por exemplo), assume uma característica de complexidade quando são 
considerados todos os aspectos referentes às diferentes nuances de rendimento dos jogadores. Esse mesmo JCE aponta para uma relação de oposição entre duas equipes, cujos objetivos são os mesmos (ARAÚJO, 2009): o de marcar os pontos e o de evitar que os adversários os marquem.

Para contemplar seus objetivos finais os jogadores precisam desenvolver ações coordenadas que os permitam se sobrepor ao jogo adversário nas diferentes fases do jogo (ataque, defesa e transições), com objetivos específicos, chamados de princípios operacionais por Bayer (1994). Tais princípios estão relacionados com as premissas defensivas (recuperar a posse de bola, evitar a progressão adversária e evitar a marcação do ponto) e ofensivas (manter a posse da bola, progredir em direção ao alvo e marcar o ponto), citadas pelo mesmo autor. Cabe ressaltar que para a compreensão dos fenômenos do jogo, manifestados em um cenário complexo, as relações de interação entre companheiros e adversários não permitem considerações reducionistas, que tendem a fornecer análises superficiais da estrutura dos JCE's.

Não obstante da mudança de paradigma descrita (baseada em VASCONCELLOS, 2002; que apresenta a tendência em compreender os fenômenos de forma complexa), as métodos de ensino dos JCE's passaram, e ainda passam, por alterações nas considerações relacionadas à complexidade desse fenômeno. $\mathrm{O}$ jogo era apresentado aos jogadores como fragmentos de unidades (ou as chamadas habilidades motoras básicas) e seu ensino era balizado por práticas reducionistas (que se caracteriza por simplificar os elementos do todo - o jogo - e, ainda, que busca a maestria na execução das técnicas - ou fundamentos - da modalidade alienadas do contexto do jogo), principalmente ao considerarmos o final da década de 80 ( $\underline{R E I S}$, 2006), quando ocorre maior acentuação de um movimento reformador no ensino dos JCE's a partir de novos modelos (MESQUITA et al., 2009). É permitido afirmar, portanto, que há uma tendência, observada, na migração do pensamento que privilegia a visão mecanicista em direção à uma visão complexa da realidade (TÔRRES, 2005), inclusive nos métodos de ensino dos JCE's.
Um dos fatores que não pode ser isolado é o que retoma à idéia de que as soluções encontradas por um jogador vão afetar diretamente as ações dos demais, partindo do pressuposto de que há um cenário técnico-tático configurado de caráter dinâmico e complexo. Com base nas alterações do referido cenário, outros fatores devem ser postos em relevância e influenciam diretamente no grau de complexidade do jogo, tais como: a) as ações individuais dos jogadores, que estão repletas de singularidades e de variabilidades técnicas, influenciadas pelas experiências prévias e mesmo pelo estágio de desenvolvimento do jogador; b) as combinações coletivas entre os jogadores, sejam essas ocorridas pela interação entre companheiros, pela relação de oposição, ou conjuntamente ao considerar as possibilidades de oposição e cooperação entre os jogadores; c) as relações espaço-temporais-situacionais (MENEZES, 2011) dos jogadores com as estruturas fixas e variáveis do jogo (BAYER, 1987); e d) os métodos de ensino aos quais os jogadores são submetidos.

Há ainda um importante conceito formulado pelos estudiosos das teorias dos sistemas dinâmicos, denominado de auto-organização. Esse conceito fundamenta-se no aparecimento de novos padrões ou, nesta pesquisa, de diferentes comportamentos táticos individuais e coletivos que objetivem romper com antigos padrões ou com a estabilidade dos sistemas. Tal emergência deriva-se, em grande parte, das inter-relações entre os protagonistas do jogo e das alterações qualitativas e quantitativas de suas relações ao longo de um processo (do jogo).

Essas mudanças no cenário técnico-tático do jogo podem ser influenciadas por um processo de ensino-aprendizagem-treinamento (ou EAT, trilogia que, para GRECO, 1995, tem a aprendizagem e o ensino concretizados a partir do treinamento) ou mesmo pela prática informal dos JCE's. Sendo assim, os métodos de ensino dos JCE's (GRECO, 2001: analítico-sintético, global-funcional, TGfU entre outros) visam 0 provimento de informações (a partir de diferentes estímulos) aos jogadores para que esses possam perceber o cenário técnico-tático do jogo e tomar suas decisões inteligentemente e de forma contextualizada.

A partir do entendimento de que a realidade humana não seja exclusivamente dicotômica (ou apenas o seja em algumas situações, como 
sugerido por MUNNÉ, 2007), ao transferirmos esse olhar para os JCE's imediatamente nos deparamos com um pensamento não-linear e não dicotômico dos jogadores em função das situações que lhes são apresentadas. Nas situações com as quais os jogadores se deparam estão envolvidos, nos processos determinantes da tomada de decisão do jogador, aspectos como a percepção e antecipação (GRECO, 1992), as influências da subjetividade em relação à análise da situação que permitem, a partir de expressões como "depende" e "talvez", demonstrar o entendimento que o jogador tem do cenário técnico-tático e das suas possibilidades de intervenção.

Essas possibilidades de intervenção de um jogador em uma situação de jogo são influenciadas pela forma que tal situação é observada e analisada pelo jogador, fundado nos modelos mentais que consegue sistematizar e interpretar, tendo os fatores limitantes do jogo como parâmetros preponderantes para a sua tomada de decisão que, para Paula et al. (2000, p.23), "é um processo multifatorial e complexo, porque é fruto da interação de diferentes fatores que a constituem". Os modelos nos quais o jogador concebe o jogo, planifica e constrói suas formas de atuação (ou tomadas de decisão) estão fortemente relacionadas com o método aos quais estão submetidos. Sendo assim, processos como a percepção, a antecipação e a tomada de decisão, que constituem os pilares da formação de jogadores inteligentes (GRECO, 1992), estão inter-relacionadas com as atitudes estratégicotáticas, ou possibilidades de decisão a serem tomadas em situações arbitrárias.

Concatenando tais conceitos com o ensino dos JCE's, há a concordância com a afirmação de Garganta (1998, p.21) de que a "construção de tal atitude, a seleção do número e qualidade das ações depende obviamente do conhecimento que o jogador tem do jogo", o que aponta para métodos que objetivem estimular os jogadores da forma mais variada possível, não apenas visando os mesmos fins aplicando jogos ou exercícios variados para um mesmo elemento (como passes, chutes e arremessos, por exemplo), mas com números variados de estímulos e integração de diferentes elementos.

Um importante ponto a ser considerado referese ao "por que" do ensino dos JCE's de maneira reducionista, que gera uma ruptura com a complexidade do cenário técnico-tático do jogo, provocada pela aleatoriedade e simultaneidade das ações dos jogadores. Ao mesmo tempo, rompe-se ainda com a estrutura coletiva, que Teodorescu (1984 apud GARGANTA, 1995, p.15) denomina de "microsistema social complexo e dinâmico", a partir da concomitante simplificação das situações-problemas oriundas das relações dos jogadores.

Estabelecendo uma relação dessas afirmações com o ensino dos JCE's, há a concordância com os apontamentos estabelecidos por Reverdito e Scaglia (2009, p.161), que consideram que os processos de EAT dos JCE's "ainda estão submetidos a alguns fatores que não refletem toda a abrangência $e$ pluralidade requerida em sua prática pedagógica". Essa redução da pluralidade do jogo pode ser evidenciada, dentre outros fatores, pela fragmentação desse em partes cada vez menores (ou redução dos aspectos relevantes do jogo, conforme SANTANA, 2005) e desconsiderando os problemas relacionados à interação dos jogadores, seja pela cooperação entre jogadores da mesma equipe ou pela oposição entre jogadores adversários.

Greco (2001) descreve as características dos métodos de ensino dos JCE's, dividindo-os em: a) método analítico (ou parcial) e suas variações, derivados da teoria Associacionista, caracterizado pelo ensino das habilidades motoras por partes, sendo essas pré-requisitos para o jogo; b) método global, onde o jogador aprende a jogar "jogando", e baseia-se na importância do jogo de forma indissociável e organizada enquanto conjunto, e não apenas como a soma de habilidades $e$ capacidades; c) o "conceito recreativo dos jogos esportivos coletivos" (GRECO, 2001, p.55), que é uma variação do método global que inclui características do método analítico (como a seriação de parâmetros); d) o ensino do jogo a partir de sua compreensão (denominada de Teaching Games for Understanding), na qual enfatiza-se os processos conscientes e intencionais para a aquisição de conhecimentos táticos na busca das soluções para as situaçõesproblema.

\section{Discussões}

A melhoria das relações de EAT é entendida neste trabalho, diante das explanações apontadas anteriormente, numa perspectiva de tentativa de aproximar ao máximo os métodos de ensino dos 
JCE's em relação às diferentes manifestações no/do jogo, principalmente considerando os aspectos $\mathrm{e}$ as relações complexas entre os jogadores (companheiros e/ou adversários).

A partir da afirmação de Tôrres $(2005$, p.5) de que a "realidade é inacabada, é um eterno e caótico fluir", e que aqui permite uma analogia com a dinâmica dos JCE's, cabe apontar que a situação caótica no contexto esportivo é mais do que um estado, mas uma constância (não uma constância de situações ou de repetitibilidade de eventos, mas a constante manutenção de um contexto de relações inconstantes). Apontamentos sobre as reais e emergentes possibilidades e objetivos do processo de ensino dos JCE's partem do pressuposto de que, se o contexto do mesmo é caótico, complexo e nãolinear por definição, busca-se 0 ensino contextualizado, e não apenas de seus fragmentos, em uma prática reducionista.

Não cabe aqui uma discussão sobre a importância dos fatores individuais e coletivos, mas é permitido apontar, após compreender a importância dos fatores inerentes à dinâmica do jogo, que desconsiderar os fatores coletivos no processo de EAT é uma conduta que parece equivocada quando na busca da formação de jogadores inteligentes e críticos.

É interessante, então, que haja a aplicação de um método de EAT que proporcione ao jogador, frente à complexidade imposta pela situaçãoproblema, selecionar a resposta mais conveniente para obter êxito naquela fase do jogo (ofensiva, defensiva ou de transições). Deve-se observar, também, a estrutura do jogo ao qual esse indivíduo é submetido, principalmente às características de aleatoriedade e descontinuidade das ações e, ainda, sobre os desafios lançados pela complexidade ao imaginário do aprendiz.

Sendo assim, deve-se desenvolver nos jogadores a intencionalidade do desenvolvimento de suas atitudes, e que seja proporcionada a esses a capacidade de decidir sobre "o que", "quando", "porque" e "como" fazer, respostas estas que correspondem a parâmetros imprescindíveis de compreensão do jogo (GARGANTA, 1998; PAULA et al., 2000), mesmo diante de situações de alta complexidade e aleatoriedade.
Os JCE's agregam a incontestável característica de um sistema dinâmico que, em seu decorrer, há a constante busca pela relação equilíbrio-desequilíbrio. Quando Garganta (1998, p.21) afirma que, em condições de ataque ou defesa "as sucessivas configurações que o jogo vai experimentando resultam da forma como ambas as equipes geram as relações de cooperação e oposição em função do objetivo do jogo", fica explícita a referida relação de forças de tentar equilibrar-se como sistema (por exemplo, quando da posse de bola por uma determinada equipe), enquanto o adversário (sem a posse da bola) tem o desequilíbrio e a incerteza das decisões a serem tomadas por aqueles. Porém, há uma inconstante propriedade na busca simultânea de equilibrar-se enquanto sistema, contemplada por Gonçalves et al. (1995, p.9) na afirmação de que "a não-linearidade essencial dos sistemas em desenvolvimento é refletida tanto na capacidade do sistema para se autoorganizar como em mudanças de estado para perda da estabilidade".

Busca-se então, no ensino dos JCE's, a ordem ou a desordem do comportamento dos jogadores e das suas possibilidades de intervenção para a resolução das situações-problema? Entende-se, nesta pesquisa, que a desordem (respeitando os elementos específicos de cada modalidade) passa a ser um elemento balizador do método de ensino adotado.

Concordando com Santana (2005, p.4), que afirma que "o objetivo dessa desordem é criar uma nova ordem", entende-se que essa nova ordem constitui a compreensão das situaçõesproblema que se apresentam e nas possibilidades de intervenção dos jogadores. São criadas então, a partir dessa "ordem pós-desordem", novas situações de desequilíbrio (desordem) e tentativas de buscar uma organização individual e/ou coletiva (ordem). O ciclo ordem-desordem, manifestado de forma complexa e integrativa, é dotado de contínuos processos de percepção e de decisões a serem tomadas.

\section{Considerações Finais}

A compreensão de que a complexidade está presente em qualquer situação-problema com a qual os jogadores se deparam durante a prática dos JCE's sugere a idéia de que os fatores relativos aos estímulos que serão proporcionados a esses durante 0 processo de ensinoaprendizagem devam ser, assim como o caráter 
do jogo, dotados de fenômenos não-lineares e aleatórios.

Os conceitos dos diferentes métodos de ensino dos JCE's devem ser entendidos como possibilidades educacionais, baseando-se em diferentes estímulos (de ordem simples ou, principalmente, complexa), que não contemplem fatores como o constante reducionismo do jogo a simples esquemas de movimento, a especialização precoce e modelos tidos como "ideais" a serem perseguidos (seja de habilidades motoras, de jogadores ou de esquemas táticos).

Deve-se considerar então, parafraseando Morin (2003, p.176), "a complexidade como desafio e uma motivação para pensar" e, ainda, como um "esforço para conceber um incontornável desafio que o real lança a nossa mente". Assim sendo, considerar a complexidade como integrante do método de ensino dos JCE's baseia-se em ter como princípio o desenvolvimento do pensamento crítico do jogador em função da situação-problema com a qual esse se depara. Está agregada nesse âmbito a possibilidade do surgimento de diferentes respostas adequadas ao contexto técnico-tático, podendo ser explorada a partir da interpretação e da reflexão que os jogadores têm de tais situações.

Menezes (2010, p.12) afirma que no ensino dos JCE's deve considerar aspectos como "visar a pluralidade das situações de jogo e [...] a formação de jogadores com amplos espectros de atuação, com boa capacidade de tomada de decisão baseada na percepção das ações", sejam essas ações ofensivas, defensivas, de transição, dos companheiros ou dos adversários. Sendo assim, o método de ensino, voltado tanto aos aspectos da iniciação como até mesmo do alto nível de rendimento deve ser pautada, inclusive, a partir de fatores e situações-problema que contemplem a aleatoriedade dos eventos e a imprevisibilidade das ações.

\section{Referências}

ARAÚJO, D. O desenvolvimento da competência táctica no desporto: o papel dos constrangimentos no comportamento decisional. Motriz. Revista de Educação Física. UNESP, Rio Claro, v. 15, n. 3, p. 537-540, 2009.

BAYER, C. Técnica del balonmano: la formación del jugador. Barcelona: Editorial Hispano Europea S.A., 1987.
BAYER, C. O ensino dos desportos colectivos. Lisboa: Dinalivros, 1994.

CAPRA, F. A teia da vida. São Paulo: Cultrix, 1996.

GARGANTA, J. Para uma teoria dos jogos desportivos colectivos. In: GRAÇA, A.; OLIVEIRA, J. (Ed.) O Ensino dos Jogos Desportivos. Porto: Faculdade de Ciências do Desporto e de Educação Física. Porto: Centro de Estudos dos Jogos Desportivos, 1995. p. 11-25.

GARGANTA, J. O ensino dos jogos desportivos colectivos: perspectivas e tendências.

Movimento, Porto Alegre, ano IV, n.8, 1998.

GLERIA, I.; MATSUSHITA, R.; DA SILVA, S. Sistemas complexos, criticalidade e leis de potência. Revista Brasileira de Ensino de Física, São Paulo, v. 26, n. 2, p. 99-108, 2004.

GODOY, M.F.; TAKAKURA, I.T.; CORREA, P.R. Relevância da análise do comportamento dinâmico não-linear (Teoria do Caos) como elemento prognóstico de morbidade e mortalidade em pacientes submetidos à cirurgia de revascularização miocárdica. Arq. Ciências da Saúde, São Paulo, v. 12, n. 4, p. 167-171, 2005.

GONÇALVES, G.A.C.; GONÇALVES, A.K.; PEROTTI JÚNIOR, A. Desenvolvimento motor na teoria dos sistemas dinâmicos. Motriz. Revista de Educação Física. UNESP, Rio Claro, v. 1, n. 1, p. 8-14, 1995.

GRECO, P.J. La formación de jugadores inteligentes. Revista Stadium, Buenos Aires, ano 26, p. 22-30, 1992.

GRECO, P.J. O ensino do comportamento tático nos jogos esportivos coletivos: aplicação no handebol. 1995. 224f. Tese (Doutorado em Educação) - Universidade Estadual de Campinas, Faculdade de Educação, 1995.

GRECO, P.J. Métodos de ensino-aprendizagemtreinamento nos jogos esportivos coletivos. In: GARCIA, E.S.; LEMOS, K.L.M. Temas Atuais VI em Educação Física e Esportes. Belo Horizonte: Saúde Ltda., 2001. p. 48-72.

GUTIÉRREZ-DÁVILA, M.; DAPENA, J.; CAMPOS, J. The effect of muscular pre-tensing on the sprint start. Journal of Applied Biomechanics, Champaign, v. 22, p. 194-201, 2006.

HUGHES, M.D.; FRANKS, I.M. Notational analysis of sport. London: E \& FN SPON, 1997.

MENEZES, R.P. Análise cinemática das trajetórias de jogadores de handebol obtidas 
por rastreamento automático. 2007. $132 \mathrm{f}$. Dissertação (Mestrado em Educação Física), Universidade Estadual de Campinas, Faculdade de Educação Física, 2007.

MENEZES, R.P. O ensino dos sistemas defensivos do handebol: considerações metodológicas acerca da categoria cadete. Pensar a Prática, Goiânia, v. 13, n. 1, p. 1-16, 2010.

MENEZES, R.P.; REIS, H.H.B. Análise do jogo de handebol como ferramenta para sua compreensão técnico-tática. Motriz, v. 16, n.2, p. 458-467, 2010.

MENEZES, R.P. Modelo de análise técnicotática do jogo de handebol: necessidades, perspectivas e implicações de um modelo de interpretação das situações de jogo em tempo real. 2011. 303f. Tese (Doutorado em Educação Física) - Universidade Estadual de Campinas, Faculdade de Educação Física, 2011.

MERCADANTE, L.A.; MENEZES, R.P.; MARTINI, T.P.; TRABANCO, J.L.A.; BARROS, R.M.L. Análise cinemática tridimensional do lançamento do martelo em treinamento e competição. In: Anais do XII Congresso Brasileiro de Biomecânica, p. 901-906, 2007.

MESQUITA, I.M.R.; PEREIRA, F.R.M.; GRAÇA, A.B.S. Modelos de ensino dos jogos desportivos: investigação e ilações para a prática. Motriz. Revista de Educação Física. UNESP, Rio Claro, v. 15, n. 4, p. 944-954, 2009.

MORIN, E. Ciência com consciência. $7^{\text {a }}$ ed. Rio de Janeiro: Bertrand Brasil, 2003.

MUNNÉ, F. El retorno de la complejidad y la nueva imagen del ser humano: hacia uma psicologia compleja. Revista Interamericana de Psicología, Austin, v. 38, n. 1, p. 23-31, 1994.

MUNNÉ, F. ¿La explicación del comportamiento humano debe ser lo más simple posible o lo más compleja posible? Encuentros en Psicología Social (Universidad de Málaga), v. 4, p. 3-10, 2007.

PAKENAS, A.; SOUZA JÚNIOR, T.P.; PEREIRA, B. Dinâmica não-linear e exercício físico: conceitos e aplicações. Revista Brasileira de Medicina do Esporte, São Paulo, v. 13, n. 5, p. 331-335, 2007.

PAULA, P.F.A.; GRECO, P.J.; SOUZA, P.R.C. Tática e processos cognitivos subjacentes à tomada de decisão nos jogos esportivos coletivos. In: GARCIA, E.S.; LEMOS, K.L.M. Temas Atuais V em Educação Física e Esportes. Belo Horizonte: Saúde Ltda., 2000. p. 11-27.
PERS, J.; BON, M.; KOVACIC, S.; SIBILA, M.; DEZMAN, B. Observation and analysis of largescale human motion. Human Movement Science, Amsterdam, 21(2), p. 295-311, 2002.

REIS, H.H.B. O ensino dos jogos coletivos esportivizados na escola. 1994. $75 \mathrm{f}$. Dissertação (Mestrado em Educação Física) Universidade Federal de Santa Maria, Centro de Educação Física e Desporto, 1994.

REIS, H.H.B. O ensino do handebol utilizando-se do método parcial. Lectures em Educación Física y Deportes, Buenos aires, Ano 10, n. 93, 2006. Disponível em:

$<$ http://www.efdeportes.com/efd93/handebol.htm>. Acesso em: 16 set. 2010.

REVERDITO, R.S.; SCAGLIA, A.J. Pedagogia do esporte: jogos coletivos de invasão. São Paulo: Phorte Editora, 2009.

SANTANA, W.C. Pedagogia do esporte na infância e complexidade. In: PAES, R.R.; BALBINO, H.F. Pedagogia do esporte: contextos e perspectivas. Rio de Janeiro: Guanabara Koogan, 2005. p.1-24.

TÔRRES, J.J.M. Teoria da complexidade: uma nova visão de mundo para a estratégia. I Encontro Brasileiro de Estudos da Complexidade (EBEC), Curitiba, 2005.

VASCONCELLOS, M.J.E. Pensamento sistêmico: o novo paradigma da ciência. Campinas: Papirus, 2002.

Endereço:

Rafael Pombo Menezes

Rua das Camélias, 85/304, Jardim das Rosas Itu SP Brasil

13309-510

Telefone: (11) 9431-2631

e-mail: rafael.pombo@yahoo.com.br

Recebido em: 12 de maio de 2010. Aceito em: 23 de novembro de 2011.

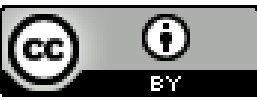

Motriz. Revista de Educação Física. UNESP, Rio Claro, SP, Brasil - elSSN: 1980-6574 - está licenciada sob Creative Commons - Atribuição 3.0 